\title{
Effects of Different-Term Acute Swimming Exercises on Oxidative Stress Parameters in Rat Cerebellum Tissue
}

\author{
Öznur AKYÜZ \\ Celal Bayar University, Manisa, Turkey
}

\begin{abstract}
Background: Regular physical activity may prevent the onset of a large range of pathological conditions, from heart diseases to mental disorders (depression, anxiety, panic disorder, social phobia, etc.), ischemia, and neurodegenerative diseases. Although beneficial effects of exercise are not known exactly for molecular mechanisms, several hypotheses have been proposed about this research. The purpose of this study is to examine the acute effects of oxidative stress parameters on the cerebellum tissue of the different swimming exercises.

Methods: Telve week-old male Albino Wistar rats $(n=32)$ were used in this study. Rats were divided randomly into four groups: control, short-term exercise (15 mins.), moderate-term exercise (30 mins.), and long-term exercise (60 mins.) group. Glass tank containing water for swimming exercise ( $\mathrm{L} \times \mathrm{W} \times \mathrm{H}, 100 \times 50 \times 50 \mathrm{~cm}$ ) was used as pool.

Results: The differences among superoxide dysmutase (SOD), glutathione (GSH), and malondialdehyde (MDA) were studied. When the difference were examined between SOD levels, short-term and moderate-term exercise groups were statistically significant different from other groups $(p<0.05)$. When GSH levels were examined, moderate-term and long-term groups were statistical different than other groups $(p<0.05)$. When MDA levels were examined, all exercise groups being compared with the control group had statistically significant differences $(p<0.05)$.
\end{abstract}

Conclusions: SOD, GSH, and MDA levels were found to be higher in the moderate-term exercising rat's cerebellum tissue compared to rats that other groups.

Keywords: cerebellum tissue, swimming exercise, oxidative stress

\section{Introduction}

Regular physical activity may prevent the onset of a large range of pathological conditions, from heart diseases (Duruturk, Tonga, Karatas, \& Doganozu, 2015) to mental disorders (depression, anxiety, panic disorder, social phobia, etc.) (Zschucke, Gaudlitz, \& Ströhle, 2013), ischemia, and neurodegenerative diseases (Nakae \& Tsushima, 2014). Although beneficial effects of exercise are not known exactly for molecular mechanisms, several hypotheses have been proposed about this research. Increasing physical activity and muscle contractions during exercise and metabolic activity accelerates energy consumption significantly. Depending on the metabolic activity of the mitochondrial electron leakage from oxygen and electron transport chain used is increasing. After all, many reactive oxygen species comes to light. This increases lipid

Öznur AKYÜZ, Ph.D., associate professor, Department of Sports Health, School of Physical Education and Sports, Celal Bayar University. 
peroxidation (Gleeson \& Bishop, 2000). Formation of reactive oxygen species (ROS) and many defense mechanisms got advanced in the body to prevent damage caused by them. Lipid peroxidation is a process generated naturally in small amounts in the body, mainly by the effect of several ROS. These ROS readily attack the polyunsaturated fatty acids of the fatty acid membrane, initiating a self-propagating chain reaction. The destruction of membrane lipids and the end-products of such lipid peroxidation reactions are especially dangerous for the viability of cells, even tissues (Mylonas \& Kouretas, 1998).

In addition to the fact that physical exercise has numerous benefits on health, there are also findings that formation of ROS and free radicals increases particularly during intensive exercise and oxidative damage occur in muscles, liver, blood, and other tissues (Kaur \& Kapoor, 2001). Performance is dependent on anaerobic power in exercise, which is performed physiologically at maximum effort, i.e. high intensity for a short duration (Pikulski \& Brodbelt, 2003).

\section{Literature Review}

Positive effects of exercise on human health are accepted and the importance of integration of sports in our daily life is increasing day by day. Getting fit through exercise contributes to reduction in the risk of developing diseases, such as cardiovascular diseases, chronic respiratory tract diseases, diabetes mellitus, obesity, cancer, osteoporosis, and psychological disorders and anxiety, and also to taking symptoms of diseases under control. In addition, exercise increases burning of excess fat in body, helps to reach the ideal body weight by losing weight, strengthens muscles, increases blood flow, energy, circulation, bone density and self-confidence, and makes the person feel better.

The higher the exercise density, the more formation of free radical occurs (Rice, Miller, Bolwell, Bramley, \& Pridham, 1995). Production of free radicals in rat musculoskeletal and myocardium tissue homogenates was observed to have increased following single consumer treadmill exercise. During the exercise, production of free radicals increases in parallel to the increase in oxygen consumption. Acute exercise causes muscular tissue damage, lipid reproduction in membranes, and formation of free radicals spectrum. In damaged tissue, phospholipase leads to proteinase enzyme activation and arachidonic acid release in cell membranes, which causes increase in production of free radical (Bando, Wakamatsu, \& Terao, 2007).

Increasing in connection with the increase of oxygen consumption, free radicals are neutralised by a defense system that contains enzymatic and non-enzymatic anti-oxidants. Exercise creates an inbalance between ROS and anti-oxidants called oxidative stress (Von, 2006). Size of the oxidative damage, which may occur during physical exercises, is determined not only by production of free radicals, but also the defense capacity of anti-oxidants. Superoxide dysmutase (SOD) and catalase (CAT) provide the first line of defense against the ROS produced during exercise. SOD (superoxide dismutase), CAT (catalase), GPx (glutathione peroxidase), and GST (glutathione-S-transferase) are among the primary anti-oxidant enzymes within enzymatic systems effective at cellular level. It is stated that an acute exercise can affect activites of these enzymes directly. Vitamin E, vitamin $\mathrm{C}$, glutathione (GSH), and flavonoids can be given as example for non-enzymatic anti-oxidants. Flanavoids are one of the largest groups of polyphenols forming through natural means. They exist in many plants. They have anti-oxidant, anti-microbial, anti-viral, and anti-bacterial properties. Flavonoids have been known as herbal pigments for more than a century. They are of polyphenolic compounds and have spreaded over all plants. In vitro studies, their anti-oxidant properties and property to catch anti-oxidants have drawn attention. Various vegetable food and beverages (fruits, vegetables, tea, cacao, and wine) are rich in flavonoids (Prior, Wu, \& Scaich, 2005). 
Anti-oxidant substances ( $\alpha$-tocopherol [vitamin E]), $\beta$-carotene, ascorbic acid (vitamin $\mathrm{C}$ ), and folic acid prevent damages stimulated by oxidation at cellular level by preventing formation of active oxygen or by cleaning the active oxygens formed, reducing Deoxyribose Nucleic Acid (DNA) deformations and peroxidations of fats and taking part in repair of damages occurring, and hence stop formation of degenerative diseases. The most important phenolic compounds of grape, which is a member of the vitaceae family, are phenolic acids, anthocyanidins, flavanol glucosides, cinnamic acit derivatives, catechines, and proanthocyanidins (Balu, Sangeetha, Murali, \& Panneerselvam 2006; Shao, Terry, Hoek, Xie, \& Wojcik, 2009; Feng, Liu, Fratkins, \& Leblan, 2005; Devi, Badanavalu, Domenico, Narayan, \& Hindupur, 2006).

Among anti-oxidants, grape seed extract (GSE) is one of the strongest known anti-oxidants. It is a mixture of similar natural flavonoids containing proanthocyanidin and having the most effective anti-oxidant activity.

It was reported that even in the absence of disease, muscle itself produces ROS, including superoxide anions (Reid et al., 1992), hydroxyl radicals (Close, Ashton, McArdle, \& Jackson, 2005), and $\mathrm{H}_{2} \mathrm{O}_{2}$ (Reid et al., 1992). The rate of ROS production increases during vigorous exercise and high-intensity exercise (McArdle, Pattwell, Vasilaki, McArdle, \& Jackson, 2005; Ferreira \& Reid, 2008). In this context, ROS and other metabolic culprits promote fatigue (Ferreira \& Reid, 2008). It is recommended that muscle mitochondrion is one of the location of ROS production in skeletal muscle (Jackson, Pye, \& Palomero, 2007) and that ROS is a most important basis for cellular oxidative damage (Brand et al., 2004). Several pathways are included in molecular signalling within the skeletal muscle. The ROS pathway is involved in contractile protein expression, angiogenesis, mitochondrial biogenesis, and other adaptations (Lira, Benton, Yan, \& Bonen, 2010). Nevertheless, it is apparent that an increase in oxygen consumption lowers the tissue oxygen tension during muscle activity (Richardson, Noyszewski, Kendrick, Leigh, \& Wagner, 1995), which leads to heightened ROS production (Zuo, Pasniciuc, Wright, Merola, \& Clanton, 2003).

Oxidative stress begins when the production of ROS is not sufficiently balanced by antioxidant species, which neutralize them (Andreazza, 2012). For example, the generation of a superoxide anion, a powerful ROS, is typically neutralized by the antioxidant enzyme SOD to protect the cell from oxidative stress. However, excessive concentrations of superoxide may overwhelm SOD and form a hydroxyl radical after reacting with water.

There are studies that show the different effects the antioxidant defense system markers of exercise (SOD, GSH, and malondialdehyde [MDA]) on the literature (Clarkson \& Thompson, 2000; Kakarla, Vadluri, \& Reddy, 2005; Finaud, Lac, \& Filaire, 2006). In this case, lipid peroxidation being found at different levels in different tissues, membrane tissue and the fat dietary fatty acids may be dependent on different levels affection. Or it can be considered that these different results stem from the intensity of the exercise, the duration of exercise, and/or the sample group. In this context, the aim of this study is to determine the effect on markers of antioxidant found in the cerebellum tissue of the acute swimming exercise at different times.

\section{Materials and Methods}

\section{Animals}

Thirty-two male rats (12 weeks old, Albino-Wistar), fed with standard laboratory chow and water that were used in this study. Animal experimentations were approved by the Ethical Committee of the Ataturk University and carried out in an ethically proper way by following the guidelines provided. 


\section{Experimental Design}

The rats used in the study were divided into four groups: the control group, short-term exercise group (15 mins.), moderate-term exercise group (45 mins.), and the long-term exercise group (60 mins.). Acute swimming exercise was performed in three training glass tanks $(100 \times 50 \times 50 \mathrm{~cm}, \mathrm{~L} \times \mathrm{W} \times \mathrm{H})$ containing water for three experimental groups.

\section{Biochemical Study}

Biochemical investigation of cerebellum tissues. After gross morphological examination, cerebellar tissues were stored at $86{ }^{\circ} \mathrm{C}$. A $100 \mathrm{mg}$ of tissues from each rat was perfused with phosphate buffered saline (PBS)/heparin and then homogenized in a specific homogenate tampon on ice by ultra-turrax after grinding in liquid nitrogen. Then they were centrifuged according to the manufacturer's instructions. For biochemical analysis, SOD activity and MDA and GSH levels from each supernatant were measured in duplicates with a sensitive kit (Cayman-706002, USA), and Cell Biolabs-STA-330 and 312 (USA), respectively, specifically designed for rat tissue. The protein concentrations were determined according to the Lowry's method (Sigma Aldrich, Total protein kit (TP0300-1KT, USA). All the data were presented as the mean seven standard deviation $(S D)$ results based on per mg of protein.

SOD measurement. Cayman's SOD Assay Kit was used for this measurement. It utilizes a tetrazolium salt for detection of superoxide radicals generated by xanthine oxidase and hypoxanthine. One unit of SOD is defined as the amount of enzyme needed to exhibit $50 \%$ dismutation of the superoxide radical. The assay measures all three types of SOD $(\mathrm{Cu} / \mathrm{Zn}, \mathrm{Mn}$, and Fe SOD). There are two total SOD activity, such as cytosolic and mitochondrial. To separate the two enzymes, supernatant was centrifuged at $10.000 \mathrm{~g}$ for $15 \mathrm{mins}$. at $4{ }^{\circ} \mathrm{C}$. Samples were assayed in the absence of xanthine oxidase to generate a sample background using Elisa reader at $440 \mathrm{~nm}$ of absorbance.

Total GSH measurement. The OxiSelect ${ }^{\mathrm{TM}}$ Total Glutathione Assay Kit was performed for the determination of total GSH. This approach is a quantitative assay for measuring the total GSH content within a sample glutathione/glutathione reductase reduces oxidized glutathione (GSH/GSSG). Briefly, GSSG to reduced GSH in the presence of nicotinamide adenine dinucleotide phosphate (NADPH). Subsequently, the chromogen reacts with the thiol group of GSH to produce a coloured compound that absorbs at $405 \mathrm{~nm}$. The total GSH content in unknown samples is determined by comparison with the predetermined GSH standard curve. The rate of chromophore production is proportional to the concentration of GSH within the sample. Metaphosphoric acid is provided to remove interfering proteins or enzymes from samples.

MDA measurement. The Thiobarbituric Acid Reactive Substances (TBARS) Assay Kit was used for the direct quantitative measurement of MDA. The MDA containing samples or MDA standards are first reacted with the thiobarbituric acid (TBA) at $95{ }^{\circ} \mathrm{C}$. After a brief incubation, the samples and standards were read fluorometrically. The MDA content in samples was determined by comparison with the predetermined MDA standard curve.

\section{Statistical Analysis}

Data was tested for normality with the Shapiro-Wilk test $(p>0.05)$. Analysis of variance (ANOVA) was used for comparisons between groups. Following variance analyses, least significant difference (LSD) multiple comparison test was employed in order to detect which measurement results caused the differences. 
Significance was accepted for values of $p<0.05$ with a $95 \%$ confidence interval.

\section{Results}

Comparison of oxidative stress parameters (SOD, GSH, and MDA) showed in Table 1. When SOD levels were examined, the difference between 15 and 30 mins. exercise groups were statistically significant different from that between other groups $(p<0.05)$. When GSH levels examined, the difference between 30 and 60 mins. groups were statistically different from that between other groups $(p<0.05)$. When MDA levels examined, all exercise groups being compared with the control group had statistically significant differences $(p<0.05)$.

Table 1

Comparison of Different Swimming Exercises on SOD, GSH, MDA Parameters on Cerebellum Tissue

\begin{tabular}{|c|c|c|c|c|}
\hline Groups & $N$ & $\begin{array}{l}\text { SOD } \\
\text { (U/mg protein) }\end{array}$ & $\begin{array}{l}\text { GSH } \\
\text { (nmol/mg protein) }\end{array}$ & $\begin{array}{l}\text { MDA } \\
\text { (nmol/mg protein) }\end{array}$ \\
\hline Control & 8 & $8.36 \pm 1.80 \mathrm{~b}$ & $0.64 \pm 0.19 b$ & $0.15 \pm 0.04 b$ \\
\hline $\begin{array}{l}\text { Short-term exercise } \\
\text { (15 mins.) }\end{array}$ & 8 & $10.53 \pm 2.16 \mathrm{a}$ & $0.79 \pm 0.25 b$ & $0.19 \pm 0.03 \mathrm{a}$ \\
\hline $\begin{array}{l}\text { Moderate-term exercise } \\
(30 \text { mins.) }\end{array}$ & 8 & $11.50 \pm 3.89 \mathrm{a}$ & $1.59 \pm 0.20 \mathrm{a}$ & $0.20 \pm 0.03 \mathrm{a}$ \\
\hline $\begin{array}{l}\text { Long-term exercise } \\
\text { (60 mins.) }\end{array}$ & 8 & $8.30 \pm 1.22 b$ & $1.18 \pm 0.10 \mathrm{a}$ & $0.20 \pm 0.02 \mathrm{a}$ \\
\hline
\end{tabular}

Note. $p<0.05$; ab: Represents the differences among the groups.

\section{Discussion}

ROS occurring in tissue and free radicals can damage biologically important materials, such as DNA protein, carbohydrates, and lipids. As free radicals can come from outside the body, they may also occur as a natural result of the human metabolism. Different natural defense systems in the body in response to damage of ROS keep free radicals under control. These systems are complementary to each other, since they act on different cells and different free radicals (Diplock, 1998).

In the literature, there are studies that showed the different effects on the antioxidant defense system markers (SOD, GSH, and MDA) of exercise (Clarkson \& Thompson, 2000; Kakarla, Vadluri, \& Reddy, 2005; Finaud, Lac, \& Filaire, 2006). In the research that studied the effects of exercise by separating brain into four parts, Rybak, Somani, and Ravi (1995) identified that the antioxidant markers of the experimental group comparing to the antioxidant markers of the control group were higher for each section. Purkinje cells of the cerebellum indicates development of DNA damage that begins at middle age and lasts for whole life. Even more important is that the degeneration and degree in loss of function are managed by lifelong exercise (Cui, Hofer, Rani, Leeuwenburgh, \& Foster, 2009). In this context, this study was designed to examine the acute effect on oxidative stress parameters in the cerebellum tissue of different swimming exercises.

In present study, in the SOD short-term, moderate-term, and long-term exercise group compared with the control group were examined and moderate and short time exercise produced higher SOD values compared to long-term exercise group $(p<0.05)$. Even in the absence of disease, the skeletal muscle itself produces ROS including superoxide anions (Reid et al., 1992; Kolbeck et al., 1997). The SOD value was increased with exercise, but longer exercise period of antioxidant defense system reduced lipid peroxidation and also displayed sufficient capability to cope with the increase in free radicals. The superoxide dismutase (SOD) and catalytic function have been investigated since 1969. Fang, Yang, and Wu (2002) showed that SOD levels of repeated 
sprint exercises made by the subjects had been found to have no significant differences in terms of statistics. However, Ji (1999) stated that there were studies reporting that acute exercise caused an increase in SOD levels in tissues and red blood cells of the various organs (liver, heart, and skeletal muscle).

GSH is also a major component of the cellular antioxidant systems (Fang, Yang, \& Wu, 2002). GSH consisting of glutamic acid, glycine, and cysteine is a tripeptide having more intracellular concentration. GSH, which is important for reducing agent and an important antioxidant, protects cells from the harmful effect of endogenous and exogenous origin oxidant by maintaining balance of the cell oxido-reduction (Comporti, 1987). In response to an increase in free radicals that occur in the cells, GSH oxidizes GSSG (Clarkson \& Thompson, 2000). In the present study, the differences between the GSH levels in rats' cerebellar tissue were examined; moderate and long-term exercise caused higher GSH levels compared to control and short-term exercise groups $(p<0.05)$. Even though cerebellar tissue GSH levels increased statistically in short and moderate-term exercise in rats, numerical decline in GSH levels was found when exercise duration was increased. Gohil, Viguie, Stanley, Brooks, and Packer (1998) found that long-term submaximal exercise may lead to a decrease in GSH levels. Laires et al. (1993) and Viguie et al. (1993) demonstrated similar results. Marin, Hänninen, Müller, and Klinger (1989) reported that 30 mins. treadmill exercise displayed no change of GSH levels. However, Ohno et al. (1986) and Evelo, Palmen, Artur, and Janssen (1992) reported erythrocyte glutathione reductase activity increased after exercise.

MDA is one of the substances that occurs as a result of the lipid peroxidation. It is used as an indicator of oxidative stress. MDA is a final product of lipid peroxidation and is used to show the level of oxidative damage (Fink, 2007). In the present study, the cerebellum tissue MDA was examined, and there were statistically meaningful differences in all exercise groups compared to the control group $(p<0.05)$. This situation makes us consider that the size of the rate of degeneration, which occurs in the cerebellum, may extend the duration of regeneration. Gul et al. (2001) found that MDA levels increased in 90 minutes swimming exercise in rats. Marzatico, Pansarasa, Bertorelli, Somenzini, and Della (1997) detected that MDA increased in sprint and half marathoners, while Sahlin, Ekberg, and Cizinsky (1991) detected the same in acute exercises. Toskulkao and Glinsuko (1996) had a training for 60 mins. corresponding to $70 \%$ of heart rate perform in sedentary individuals with the cycle ergometer, and detected that plasma MDA levels increased five minutes after the exercise and remained high until the 48th hour. However, Alessio et al. (2000) determined that MDA levels did not change in the aerobic exhaustion exercise, while Leaf, Kleinman, Hamilton, and Barstow (1997) determined no change in MDA levels before and after exercise in the maximal exercise.

It can be considered that these different results might be the result of different intensities, duration of exercises, and/or the sample groups. Recently, researchers have begun to investigate the effects of antioxidant system markers in different tissues of different exercise durations (short-term, moderate-term, and long-term) rather than a general exercise (Han, Cho, \& Young, 2011; Kim \& Choi, 2011; Ashrafi \& Roshan, 2012). Prior studies detected exercises performed regularly at a specified intensity increased the anti-oxidant capacity (Leaf, Kleinman, Hamilton, \& Barstow, 1997; Schröder, Navarro, Tramullas, Mora, \& Galiano, 2000). The study identified that the moderate-term exercise group had the highest level of the cerebellum antioxidant markers in the tissue.

\section{Conclusions}

It can be concluded that in acute exercises, a moderate-term exercise enhances the adaption capability by 
increasing the level of oxidative stress parameters and this may reduce lipid peroxidation levels. It was suggested that elevated lipid peroxidation in peripheral blood may indicate a systemic elevation of oxidative stress and a failure of the antioxidant system to sufficiently neutralize the increased production of reactive oxygen species (Sultana, Perluigi, \& Allan, 2013).

\section{References}

Alessio, H. M., Hagerman, A. E., Fulkerson, B. K., Ambrose, J., Rice, R. E., \& Wiley, R. L. (2000). Generation of reactive oxygen species after exhaustive aerobic and isometric exercise. Medcine and Science in Sports and Exercise, 32(9), 1576.

Andreazza, A. C. (2012). Combining redox-proteomics and epigenomics to explain the involvement of oxidative stress in psychiatric disorders. Mol Biosyst, 8(10), 2503-2512.

Ashrafi, J., \& Roshan, V. D. (2012). Is short-term exercise a therapeutic tool for improvement of cardioprotection against DOX-induced cardiotoxicity? An experimental controlled protocol in rats. Asian Pacific Journal of Cancer Prevention, 13(8), 4025-4030.

Balu, M., Sangeetha, P., Murali, G., \& Panneerselvam, C. (2006). Modulatory role of grape seed extract on age-related oxidative DNA damage in central nervous system of rats. Brain Research Bulletin, 68(6), 469-473.

Bando, N., Wakamatsu, S., \& Terao, J. (2007). Effect of an excessive intake of quercetin on the vitamin E level and an tioxidative enzyme activities of mouse liver under paraquat-induced oxidative stress. Biosci Biotechnol Biochem, 71(10), $2569-2572$.

Brand, M. D., Affourtit, C., Esteves, T. C., Green, K., Lambert, A. J., Miwa, S. et al. (2004). Mitochondrial superoxide: Production, biological effects, and activation of uncouplingproteins. Free Radic Biological Medcine, 37(6), 755-767.

Clarkson, P. M., \& Thompson, H. S. (2000). Antioxidants: What role do they play in physical activity and health? The American Journal of Clinical Nutrition, 72(2), 637-646.

Close, G. L., Ashton, T., McArdle, A., \& Jackson, M. J. (2005). Microdialysis studies of extracellular reactive oxygen species. Free Radical Biology \& Medicine, 39(11), 1460-1467.

Comporti, M. (1987). Glutathione depleting agents and lipid peroxidation. Chemistry and Physics of Lipids, 45(2), 143-169.

Cui, L., Hofer, T., Rani, A., Leeuwenburgh, C., \& Foster, T. C. (2009). Comparison of lifelong and late life exercise on oxidative stress in the cerebellum. Neurobiology of Aging, 30(6), 903-909.

Devi, L., Badanavalu, M. P., Domenico, F. G., Narayan, G. A., \& Hindupur, K. A., (2006). Accumulation of amyloid precursor protein in the mitochondrial import channels of human alzheimer's disease brain is associated with mitochondrial dysfunction. The Journal of Neuroscience, 26(35), 9057-9068.

Diplock, A. T. (1998). Defence against reactive oxygen species. Free Radical Research, 29(6), 463-467.

Duruturk, N., Tonga, E., Karatas, M., \& Doganozu, E. (2015). Activity performance problems of patients with cardiac diseases and their impact on quality of life. Journal of Physical Therapy Science, 27(7), 2023.

Evelo, C. T. A., Palmen, N. G. M., Artur, Y., \& Janssen, G. M. E. (1992). Changes in blood glutathione concentrations, and in erythrocyte glutathione reductase and glutathione-S-transferase activity after running training and after participation in contests. European Journal of Applied Physiology and Occupational Physiology, 64(4), 354-358.

Fang, Y. Z., Yang, S., \& Wu, G. (2002). Free radicals, antioxidants, and nutrition. Nutrition, 18(10), 872-879.

Feng, Y. Z., Liu, Y. M., Fratkins, J. D., \& Leblan, M. H. (2005). Grape seed extract suppresses lipid peroxidation and reduces hypoxic ischemic brain injury in neonatal rats. Brain Research Bulletin, 66(2), 120-127.

Ferreira, L. F., \& Reid, M. B. (2008). Muscle-derived ROS and thiol regulation in muscle fatigue. Journal of Applied Physiology, 104(3), 853-860.

Fink, M. P. (2007). Ethyl pyruvate: A novel anti-inflammatory agent. Journal of Internal Medicine, 261(4), 349-362.

Finaud, J., Lac, G., \& Filaire, E. (2006). Oxidative stress. Sports Medicine, 36(4), 327-358.

Gleeson, M., \& Bishop, N. C. (2000). Modification of immune responses to exercise by carbohydrate, glutamine and anti-oxidant supplements. Immunology and Cell Biology, 78(5), 554-561.

Gohil, K., Viguie, C., Stanley, W. C., Brooks, G. A., \& Packer, L. (1998). Blood glutathione oxidation during human exercise. Journal of Applied Physiology, 64(1), 115-119.

Gul, M., Oztasan, N., Taysi, S., Gumustekin, K., Akar, S., \& Bakan, N. (2001). Short-term swimming exercise as an oxidative stress model in rat. Hacettepe Journal of Sport Sciences, 12(4), 26-32.

Han, G., Cho, B., \& Young, M. T. (2011). Endurance exercise reduces oxidative stress in mice. Journal of Physical Therapy Science, 23(4), 539-541. 
Jackson, M. J., Pye, D., \& Palomero, J. (2007). The production of reactive oxygen and nitrogen species by skeletal muscle. Journal of Applied Physiology, 102(4), 1664-1670.

Ji, L. L. (1999). Antioxidants and oxidative stress in exercise. Experimental Biology and Medicine, 222(3), $283-292$.

Kakarla, P., Vadluri, G., \& Reddy, K. S. (2005). Response of hepatic antioxidant system to exercise training in aging female rat. Journal of Experimental Zoology Part A: Comparative Experimental Biology, 303(3), 203-208.

Kaur, C., \& Kapoor, H. C. (2001). Anti-oxidant activity and total phenolic content of some Asian vegetables. International Journal of Food Science and Technology, 37(2), 153-161.

Kim, S., \& Cho, B. (2011). A study of acute maximal workload on oxidative stress response with the obese. Journal of Physical Therapy Science, 23(5), 777-780.

Kolbeck, R. C., She, Z. W., Callahan, L. A., \& Nosek, A. T. M. (1997). Increased superoxide production during fatigue in the perfused rat diaphragm. American Journal of Respiratory and Critical Care Medicine, 156(1), 140-145.

Laires, M. J., Madeira, F., Sergio, J., Colaco, C., Vaz, C., \& Felisberto, G. M. (1993). Preliminary study of the relationship between plasma and erythrocyte magnesium variations and some circulating pro-oxidant and antioxidant indices in a standardized physical effort. Magnesium Research, 6(3), 233-238.

Leaf, D. A., Kleinman, M. T., Hamilton, M., \& Barstow, T. J. (1997). The effect of exercise intensity on lipid peroxidation. Medicine and Science in Sports and Exercise, 29(8), 1036-1039.

Lira, V. A., Benton, C. R., Yan, Z., \& Bonen, A. (2010). PGC-1 $\alpha$ regulation by exercise training and its influences on muscle function and insulin sensitivity. American Journal of Physiology-Endocrinology and Metabolism, 299(2), 145-161.

Marin, E., Hänninen, O., Müller, D., \& Klinger, W. (1989). Influence of acute physical exercise on glutathione and lipid peroxides in blood of rat and man. Acta Physiol Hung, 76(1), 71-76.

McArdle, F., Pattwell, D. M., Vasilaki, A., McArdle, A., \& Jackson, M. J. (2005). Intracellular generation of reactive oxygen species by contracting skeletal muscle cells. Free Radical Biology and Medicine, 39(5), 651-657.

Marzatico, F., Pansarasa, O., Bertorelli, L., Somenzini, L., \& Della, V. G. (1997). Blood free radical antioxidant enzymes and lipid peroxides following long-distance and lactacidemic performances in highly trained aerobic and sprint athletes. The Journal of Sports Medicine and Physical Fitness, 37(4), 235-239.

Mylonas, C., \& Kouretas, D. (1998). Lipid peroxidation and tissue damage. In Vivo (Athens, Greece), 13(3), 295-309.

Nakae, H., \& Tsushima, H. (2014). Effects of home exercise on physical function and activity in home care patients with Parkinson's disease. Journal of Physical Therapy Science, 26(11), 1701-1706.

Ohno, H., Sato, Y., Yamashita, K., Doi, R., Arai, K., Kondo, T., \& Taniguchi, N. (1986). The effect of brief physical exercise on free radical scavenging enzyme systems in human red blood cells. Canadian Journal of Physiology and Pharmacology, 64(9), $1263-1265$.

Pikulski, M., \& Brodbelt, J. S. (2003). Differentiation of flavonoid glycoside isomers by using metal complexation and electrospray 1onization mass spectrometry. Journal of the American Society for Mass Spectrometry, 14(12), 1437-1453.

Prior, R. L., Wu, X., \& Scaich, K. (2005). Standardized methods for the determination antioxidant capacity and phenolics in foods and dieatry supplements. Journal of Agricultural and Food Chemistry, 53(8), 3110-3113.

Reid, M. B., Haack, K. E., Franchek, K. M., Valberg, P. A., Kobzik, L., \& West, M. S. (1992). Reactive oxygen in skeletal muscle. I. Intracellular oxidant kinetics and fatigue in vitro. Journal of Applied Physiology, 73(5), 1797-1804.

Rice-Evans, C. A., Miller, N. J., Bolwell, P. G., Bramley, P. M., \& Pridham, J. B. (1995). The relative activities of plant-derived poliphenolic flavonoids. Free Radical Research, 22(4), 375-383.

Richardson, R. S., Noyszewski, E. A., Kendrick, K. F., Leigh, J. S., \& Wagner, P. D. (1995). Myoglobin O $_{2}$ desaturation during exercise. Evidence of limited $\mathrm{O}_{2}$ transport. Journal of Clinical Investigation, 96(4), 1916.

Rybak, L. P., Somani, S. M., \& Ravi, R. (1995). Effect of exercise training on antioxidant system in brain regions of rat. Pharmacology Biochemistry and Behavior, 50(4), 635-639.

Sahlin, K., Ekberg, K., \& Cizinsky, S. (1991). Changes in plasma hypoxanthine and free radical markers during exercise in man. Acta Physiol Scand, 142(2), 275-281.

Schröder, H., Navarro, E., Tramullas, A., Mora, J., \& Galiano, D. (2000). Nutrition antioxidant status and oxidative stress in professional basketball players: Effects of a three compound antioxidative supplement. International Journal of Sports Medicine, 21(02), 146-150.

Shao, Z. H., Terry, L., Hoek, V., Xie, J., \& Wojcik, K. (2009). Grape seed proanthocyanidins protect cardiomyocytes from ischemia and reperfusion injury via akt-nos signaling. Journal of Cellular Biochemistry, 107(4), 697-705. 
Sultana, R., Perluigi, M., \& Allan, B. D. A. (2013). Lipid peroxidation triggers neurodegeneration: A redox proteomics view into the Alzheimer disease brain. Free Radical Biology and Medicine, 62, 157-169.

Toskulkao, C., \& Glinsukon, T. (1996). Endurance exercise and muscle damage: Relationship to lipid peroxidation and scavenging enzymes in short and long distance runners. Japanese Journal of Physical Fitness and Sports Medicine, 45(1), 63-70.

Viguie, C., Frei, B., Shigenaga, M., Ames, B., Packer, L., \& Brooks, G. (1993). Antioxidant status and indexes of oxidative stress during consecutive days of exercise. Journal of Applied Physiology, 75(2), 566-572.

Von, S., C. (2006). Free-radical-induced DNA damage and its repair. Verlag Berlin Heidelberg New York: Springer.

Zschucke, E., Gaudlitz, K., \& Ströhle, A. (2013). Exercise and physical activity in mental disorders: Clinical and experimental evidence. Journal of Preventive Medicine and Public Health, 46(1), 12-21.

Zuo, L., Pasniciuc, S., Wright, V. P., Merola, A. J., \& Clanton, T. L. (2003). Sources for superoxide release: Lessons from blockade of electron transport, NADPH oxidase, and anion channels in diaphragm. Antioxid Redox Signal, 5(5), 667-675. 